\title{
GEOMETRIC QUALITY ASSESSMENT OF BUNDLE BLOCK ADJUSTED MULTI- SENSOR SATELLITE IMAGERIES
}

\author{
Sujata Ghosh*, P S Bhawani Kumar, P V Radhadevi, V Srinivas, J Saibaba, Geeta Varadan \\ Advanced data processing Research Institute (ADRIN), Dept of Space, Govt of India \\ 203 Akbar Road, Tarbund, Manovikas Nagar PO, Secunderabad- 500009 (AP) \\ Email-spaceadrin@gmail.com
}

Commission VIII, WG VIII/10

KEY WORDS: Bundle block adjustment, Geometric error, Accuracy, multi-sensor imagery, Cartosat-1

\begin{abstract}
:
The integration of multi-sensor earth observation data belonging to same area has become one of the most important input for resource mapping and management. Geometric error and fidelity between adjacent scenes affects large-area digital mosaic if the images/ scenes are processed independently. A block triangulation approach "Bundle Block Adjustment (BBA)" system has been developed at ADRIN for combined processing of multi-sensor, multi-resolution satellite imagery to achieve better geometric continuity. In this paper we present the evaluation results of BBA software along with performance assessment and operational use of products thus generated.

The application evaluation deals with functional aspects of block-adjustment of satellite imagery consisting of data from multiple sources, i.e. AWiFs, LISS-3, LISS-4 and Cartosat-1 in various combinations as single block. It has provision for automatic generation of GCPs and tie-points using image metafile/ Rational Polynomial Coefficient's (RPC's) and ortho/ merged/ mosaicked products generation. The study is carried out with datasets covering different terrain types (ranging from high mountainous area, moderately undulating terrain, coastal plain, agriculture fields, urban area and water-body) across Indian subcontinent with varying block sizes and spatial reference systems. Geometric accuracy assessment is carried out to figure out error propagation at scene based ortho/ merged products as well as block level. The experimental results confirm that pixel tagging, geometric fidelity and feature continuity across adjacent scenes as well as for multiple sensors reduced to a great extent, due to the high redundancy. The results demonstrate that it is one of the most affective geometric corrections for generating large area digital mosaic over High mountainous terrain using high resolution good swath satellite imagery, like Cartosat-1, with minimum human intervention.
\end{abstract}

\section{INTRODUCTION}

The integration of multi-sensor earth observation data pertaining to a particular area is one of the most crucial inputs for resource mapping, management, planning and natural hazard mitigation, which require both multispectral coarse resolution and a number of high resolution data in a timely manner. Hence, geometric processing of heterogeneous sensors need to be handled in a large single block triangulation with minimum human intervention. IRS and Cartosat series provides a stack of multi-resolution multispectral and high resolution pan imagery (i.e. AWiFs, LISS-3, LISS-4 and Cartosat-1) but mapping quality gets affected by the heterogeneity of data sources in structure, semantics and geometry of sensors. Cartosat- 1 alongtrack stereoscopic imagery (fore $+26^{\circ}$ and $-5^{\circ}$ aft) with $2.5 \mathrm{~m}$ spatial resolution (B/H ratio - 0.62) add an advantage to multiscale data synchronisation. Most common practice is inputs to the photogrammetric processing system are Rad- orthokit or Geo-orthokit (mono/stereo) along with Rational Polynomial Coefficients (RPCs) and or Level-1A image along with Ancillary data information file (ADIF). The RPCs for each image is generated using orbit attitude information of single image scene/ image strip. Geometric error and fidelity between adjacent scenes are affected in large-area digital mosaic if the images/ scenes are processed independently. A number of scenes/ strips from different sensors need to be processed as a single block with various types of reference data to achieve geometric consistency and feature continuity for state/ district/ city/ watershed level mapping. Moreover to deal with the high data volume of available satellite systems, a highly automated processing is required for cost effective timely production of large number of data products. A digital system (Bundle block adjustment and production system - BBA) with block triangulation approach is developed at ADRIN, providing full photogrammetric production line from satellite triangulations to ortho mosaics, for combined processing of multi-sensor, multiresolution data products with substantially reduced human intervention in a short time. This software system is substantiating IMGEOS requirement (BBA user Manual, 2014). In this paper we present the evaluation results of BBA software system before operationalization along with performance assesment and product quality.

\section{BBA APPROACH}

The BBA software system supports multi-sensor approach, the ability to process geometrically the imageries collected from different sensors in a single adjustment. The principle of bundle block adjustment is based on the co-linearity equation, a method to calculate the orientation parameters from ground control points and their positions in the image, precisely with RFM model and Rigorous Sensor Model (Nagasubramanian et. al, 2007 and Radhadevi et. al, 2010). Ground control points (GCPs) and Tie points are handled simultaneously in one single adjustment process which assures high geometric precision and 
fidelity. Automatic generation of control points, tie points with adjacent scene overlap areas are generated using techniques of image correlation, mutual information, edge matching etc and it is refined by blunder detection methods. The advantages of block adjustment system are -

- Reduce the number of ground control points

- Obtain a better relative accuracy between the images/ image-strips and precise mosaic over large areas

- Accurate co-registration/ pixel tagging between multisensor/ bands products

Typical satellite imagery blocks, collected across multiple seasons, over several years and under different atmospheric conditions (fog, cloud cover), contributing in 'difference in appearance' resulting in matching failures. Additionally, the image quality of varying resolution further complicates image matching resulting in problems when performing automatic tie point matching on blocks with hundreds of images.

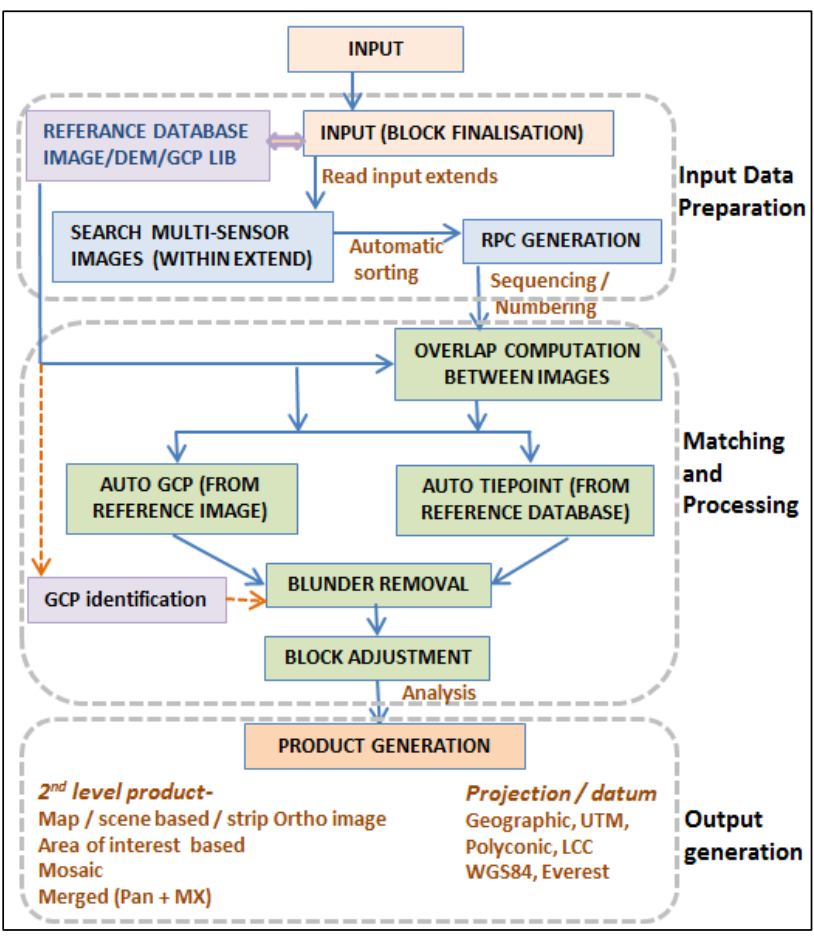

Fig -1 . Process flow at BBA software system

Input data preparation component takes care of image selection based on sensors details/metadata, Reference database preparation/ selection (Fig-1). Matching and block processing component happens without human interventions to the maximum extent. If automatic matching fails, it triggers the user to identify seed points /GCP in the failed images and the process will continue.

\section{SOFTWARE DETAILS}

Software development environment: Entire processing workflow (radiometric enhancement, points matching and measurement, images orientation/ geocoding, ortho-imagery creation), implemented in-house, is a 64-bit application developed using C++ and VS2010 (Fig-2). Software dependencies are -

- $\quad$ AIPS control and OSG control

- VC++ runtime and MSFlex GRID

- GDAL libraries

\section{- Graphics card for 3D visualization}

\section{Dependency Factors:}

- Support Resourcesat-1, 2 (AWiFs, LISS-III, LISS-IV sensors) Cartosat-1 (Mono/stereo), Cartosat-2 image as input. It can also support foreign satellites like IKONOs, Quick-bird, and World-view imagery as input.

- All raster data processing and corrections are happening in native 'AIPS' format, supported by import/export provision to convert 'to and from geotiff'

- Naming conventions are followed for images and associated files for sorting and storing input, reference and output files.

- Reference data (Land-sat ETM/ LDCM, Cartosat ortho products, SRTM, ASTER and Cartosat-1 DEMs) are part of the software internal database to make the control point and tie point generation process automatic.

- The software architecture is able to initialise sensor model directly from image metadata/ pre-stored information which is automatically accessible by the system for standard photogrammetric operations like RPC generation, resection, intersection or triangulation (Fig-1 and 2).

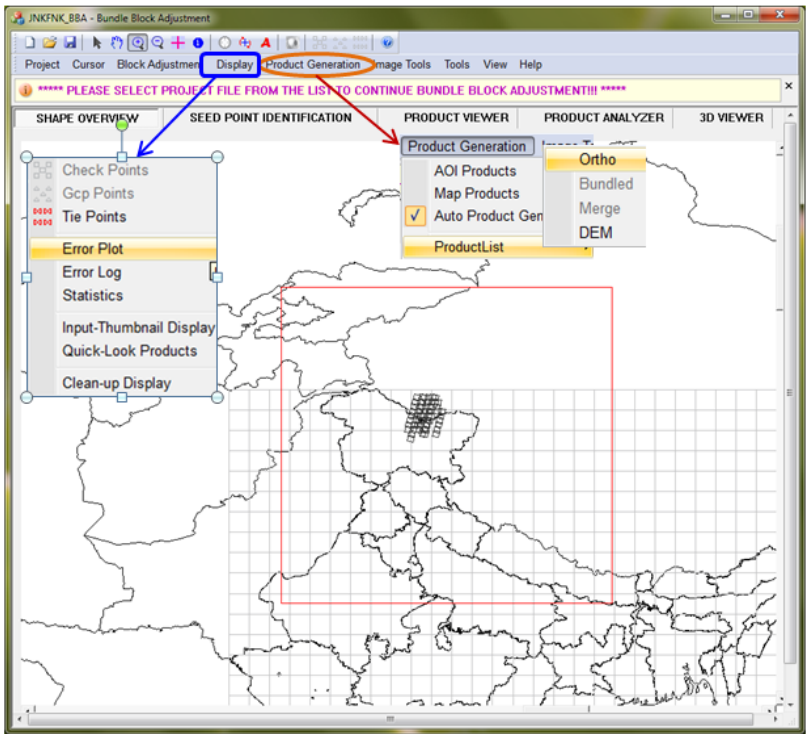

Fig-2. BBA software system indicating supported functionality

\section{TEST DETAILS}

Quality evaluation was performed before operationalization of BBA software system and assment methodology has considered the following key points -

- Geometrical model consideration and implementation

- Number and distribution of the Ground Control Points (GCP) used along with accuracy

- Accuracy and resolution of the reference data used

- System parameters considered in the implementation/ for the process

\subsection{Testing environment}

DELL INSPIRON 7600 with 32 core (2 CPU) with 16GB RAM running Windows-7 64-bit OS. 


\subsection{Data Description -}

Several images covering various geographic conditions from different sensors have been chosen over the six mentioned test sites (Table-1) keeping in mind the following factors -

1) Different terrain types to check matching robustness.

2) Multi sensor data with different types of input reference system (projection/ datum)

Level-1A Rad-corrected images with ADIF file, Orthokit with RPCs of stereo and wide mono (Cartosat-1) scene based and strip datasets are used.

\begin{tabular}{|c|c|c|c|}
\hline $\begin{array}{l}\text { Sl } \\
\text { no }\end{array}$ & Area & $\begin{array}{c}\text { Terrain } \\
\text { Type }\end{array}$ & Details (elevation/slope) \\
\hline 1 & $\begin{array}{l}\text { Andhra } \\
\text { Pradesh }\end{array}$ & $\begin{array}{l}\text { Flat terrain } \\
\text {-river delta } \\
\text { and coastal } \\
\text { area }\end{array}$ & $\begin{array}{l}\text { Elevation varies from } 1.5 \\
\text { metres in flat areas to up to } \\
100 \mathrm{~m} \text {. The area contains } \\
\text { two rivers/ canal, agri. } \\
\text { Land, aqua culture ponds, } \\
\text { wetlands with mangrove } \\
\text { vegetation, different sized } \\
\text { roads and small villages. } \\
\text { Slope variation is less and } \\
\text { except a few areas }\end{array}$ \\
\hline 2 & $\begin{array}{l}\text { Rajasthan } \\
\text { Marusthali }\end{array}$ & $\begin{array}{l}\text { Desert area } \\
\text { with sand } \\
\text { dunes }\end{array}$ & $\begin{array}{l}\text { Elevation variations are } \\
\text { from } 100 \text { to } 1000 \mathrm{~m} \text { with } \\
\text { longitudinal dune and sand } \\
\text { sheet. Slope variation is } \\
\text { minimum to moderate } \\
\text { (dune lee-ward side). }\end{array}$ \\
\hline 3 & Jharkhand & $\begin{array}{l}\text { Moderate } \\
\text { hilly area } \\
\text { with forest } \\
\text { patches } \\
\text { and plain } \\
\text { area }\end{array}$ & $\begin{array}{l}\text { Wide range of different } \\
\text { topo and morphological } \\
\text { features including dissected } \\
\text { hills (up to } 1500 \mathrm{~m} \text { ) with } \\
\text { moderate slope and } \\
\text { agricultural plains exist. A } \\
\text { number of small urban } \\
\text { settlements and a few water } \\
\text { bodies are present. }\end{array}$ \\
\hline 4 & $\begin{array}{ll}\text { Jammu } & \& \\
\text { Kashmir } & \end{array}$ & $\begin{array}{l}\text { Very high } \\
\text { mountaino } \\
\text {-us area } \\
\text { including } \\
\text { glaciers } \\
\end{array}$ & $\begin{array}{l}\text { Topography ranges from } \\
3000-55000 \mathrm{~m} \text { (very high } \\
\text { slope) with glaciers, snow } \\
\text { peaks, deep valleys, forest, } \\
\text { bare rock, grass. }\end{array}$ \\
\hline 5 & Bangaluru & $\begin{array}{l}\text { Flat terrain } \\
\text { Dense } \\
\text { urban Area }\end{array}$ & $\begin{array}{l}\text { Dense urban area } \\
\text { settlement with different } \\
\text { type of roads/ utilities } \\
\text { interrupted by small lakes } \\
\text { and agricultural land. }\end{array}$ \\
\hline 6. & Hyderabad & Urban area & $\begin{array}{l}\text { City and outskirt area with } \\
\text { gradual slope }\end{array}$ \\
\hline
\end{tabular}

Table 2: Test area details

\subsection{Test Dataset details}

A Number of scenes in each block references used and output datum projection details are mentioned in Table-2. The data processing in one block is planned to assess Cartosat-1 Geometric data processing robustness for cases which causes common error (i.e. across single row, state level area processing, area over land and ocean, area with thin cloud patch etc. as part of block processing). For multi-sensor processing in a single block, sensors can be combined whose spatial resolutions is up to 4 times. For example- Cartosat and LISS-4 can be processed in a single block but AWiFs and Cartosat can't be as the resolution differences between these two sensors are much more than 4 times.

\begin{tabular}{|c|c|c|c|c|}
\hline $\begin{array}{c}\text { SI } \\
\text { no }\end{array}$ & Area & $\begin{array}{l}\text { Sensors } \\
\text { used }\end{array}$ & $\begin{array}{l}\text { Ref } \\
\text { (control) }\end{array}$ & Projection /datum \\
\hline 1 & $\begin{array}{l}\text { Andhra } \\
\text { Pradesh }\end{array}$ & $\begin{array}{l}\text { Cartosat-1 } \\
126 \text { scenes } \\
\text { (stereo) }\end{array}$ & $\begin{array}{l}\text { ETM } \\
\text { PAN } \\
\text { SRTM-4 }\end{array}$ & $\begin{array}{l}\text { Geographic/ } \\
\text { WGS-84 }\end{array}$ \\
\hline 2 & Rajasthan & $\begin{array}{l}\text { Cartosat-1 } \\
97 \text { scenes } \\
\text { IRS-P6 L- } \\
4 \text { MX - 5 } \\
\text { scenes }\end{array}$ & $\begin{array}{l}\text { LDCM-8 } \\
\text { (PAN) } \\
\text { SRTM-4 }\end{array}$ & $\begin{array}{l}\text { Geographic/ } \\
\text { WGS-84 }\end{array}$ \\
\hline 3 & Jharkhand & $\begin{array}{l}\text { Cartosat-1 } \\
38 \text { scenes } \\
\text { (stereo) }\end{array}$ & $\begin{array}{l}\text { CARTO- } \\
1 \\
\text { ORTHO } \\
\text { SRTM-4 }\end{array}$ & $\begin{array}{l}\text { Geographic/ } \\
\text { WGS-84 }\end{array}$ \\
\hline 4 & $\begin{array}{l}\text { Jammu } \\
\& \\
\text { Kashmir }\end{array}$ & $\begin{array}{l}\text { Cartosat-1 } \\
37 \text { scenes } \\
\text { (stereo) }\end{array}$ & $\begin{array}{l}\text { ETM } \\
\text { SRTM-4 }\end{array}$ & $\begin{array}{l}\text { Geographic/ } \\
\text { WGS-84 }\end{array}$ \\
\hline 5 & Bangalore & $\begin{array}{l}\text { Cartosat-1 } \\
6 \text { scenes } \\
\text { P6 L4 MX } \\
4 \text { scenes }\end{array}$ & $\begin{array}{l}\text { ETM } \\
\text { SRTM-4 }\end{array}$ & $\begin{array}{l}\text { Geog /WGS84, } \\
\text { Polyconic/ Everest, } \\
\text { UTM /Everest, } \\
\text { UTM/WGS84, } \\
\text { Geog/Everest, } \\
\text { Polyconic/ WGS84 }\end{array}$ \\
\hline 6 & $\begin{array}{l}\text { Jammu } \\
\& \\
\text { Kashmir } \\
-\end{array}$ & $\begin{array}{l}\text { IRS-P6 L-3 } \\
6 \quad \text { scenes, } \\
\text { AWF } 4 \\
\text { scenes }\end{array}$ & $\begin{array}{l}\text { ETM } \\
\text { SRTM-4 }\end{array}$ & $\begin{array}{l}\text { Geographic/ } \\
\text { WGS-84 }\end{array}$ \\
\hline 7 & $\begin{array}{l}\text { Hyderab- } \\
\text { ad }\end{array}$ & $\begin{array}{l}\text { Cartosat-1 } \\
4 \text { scenes } \\
\text { P6 L4 MX } \\
2 \text { scenes }\end{array}$ & $\begin{array}{l}\text { Cartosat- } \\
1 \text { SRTM- } \\
4\end{array}$ & LCC/WGS-84 \\
\hline
\end{tabular}

Table 3: Details about reference and input datasets.

\subsection{Methodology -}

These test data sets belong to a period of last 5 years at different seasons, with varying sun-angle and azimuth, Cloud cover $(0 \%$ to $6 \%$ ) and existing with ADIF information or in Orthokit. The products comparison is performed using the in-house developed specific quality analysis tool and other COTS software.
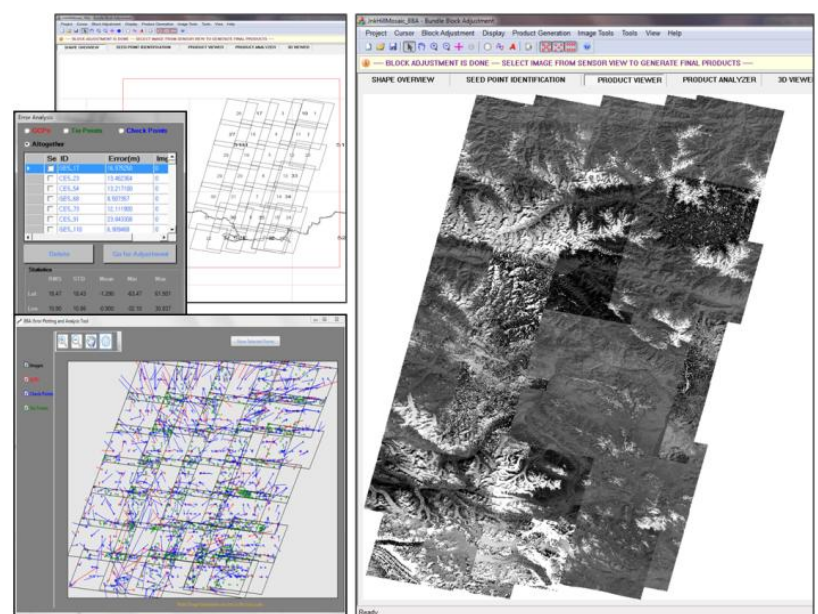

Fig- 3. Single block processed for Cartosat-1 imagery of a mountainous area with error-plot and ortho-products

The data assessment process will highlight the following aspects:

- Geometric quality assessment

- Absolute geo-location accuracy of the products, estimated against known/ input reference points. 
- Relative geometric accuracy of products on the same area (co-registration), independently from their absolute geo-location accuracy.

- Geometric fidelity across adjacent scenes

- Any other standard bias in geometry across the block

- Assessment of mosaic for seamlessness

- Radiometric fidelity and BBR of the products

The software generates Ortho, bundled and merged products depending upon input and output defined. (Fig-3). Users have to specify the ROI and sensors for generating BBA products. A number of Strip-Ortho images have been generated in semiautomatic way, using a large volume of data, to enable operational production of ortho products with low internal distortion. Initial experiments and analysis carried out promise generation of products with good geometric quality and feature matching

\section{RESULTS AND DISCUSSION}

The software is able to process a large no of imagery in a single block. Scenes with more than $60 \%$ cloud or water fail for autoGCP identification and 3 seed points per scene need to be provided by the user for further processing. The system is able to generate 50 products of Cartosat-1, processed in a single block, in 1 hour. Block adjusted following products types are evaluated-

- Ortho products

- Area of interest (AOI) ortho products

- Merged products

- Mosaic of PAN ortho images and L4 multispectral images with BBR correction

\subsection{Block adjustments of Cartosat-1 for large canvas area}

Results shows that the errors are random in nature irrespective of the position of the scene inside the block as well as within a single scene (image centre or at the sides of image). This indicates that there is no error propagation from the top left corner to bottom right corner in the block. For High mountainous area (Test area-4) geometric accuracy of Cartosat 1- Fore-camera products get affected severely by shadow of terrain peaks, which is reflected in planimetry and feature continuity (Fig-4a). Automatic matching and reference database takes care to generate points for adjustment and checking GCP (333 nos), Tie-Points (1180 nos) and Check-Points (901 nos). Final output is bundled scene-based Cartosat-1 (30X30 $\mathrm{km}$ ) mosaic ready ortho-products (Fig-3) covering 25,000 sq. $\mathrm{km}$.

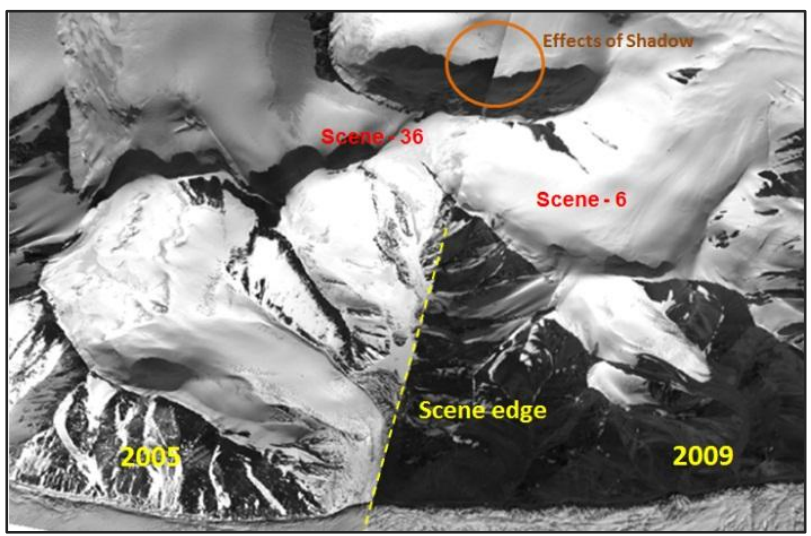

Fig-4a. Feature continuity and differences in ortho outputs

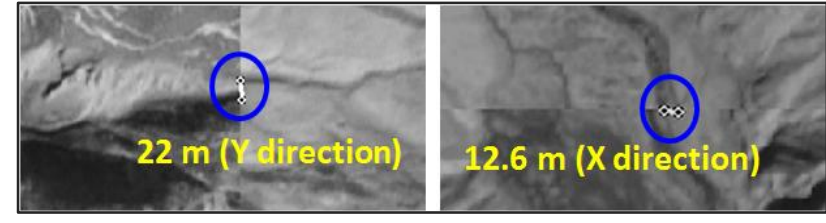

Fig- 4b. Accuracy of block adjusted products

It is observed that, in high mountainous area ortho products from AFT camera $\left(-5^{\circ}\right.$ angle) provides better geometric accuracy than Fore camera products $\left(+26^{\circ}\right.$ angle). RMSE of the entire block is $20.68 \mathrm{~m}$ in latitudinal direction and $12.64 \mathrm{~m}$ in longitudinal direction. Observed maximum planimetric error is $22 \mathrm{~m}$ in adjacent path Cartosat-1 ortho products from AFT camera (Fig-4b). Ortho correction with control points from ETM-pan data can give a planimetric accuracy of $\pm 30 \mathrm{~m}$ for entire block without any specific error bias.

Single block processing of test area -3 and test area- 1 shows an excellent feature continuity in adjacent Cartosat scenes (Fig-5 and $7 \mathrm{a}$ and $7 \mathrm{~b}$ ) i.e 3-4 pixel of input image (7-12 m) in both $\mathrm{X}$ and $\mathrm{Y}$ direction and no specific error bias is observed. Toutin (2004) in his review article reported that the number of GCPs required for satellite imagery correction was derived from a function of different conditions, i.e - collection method, sensor type and resolution, geometric model, physical environment of study site, GCPs definition \& accuracy and final expected accuracy.

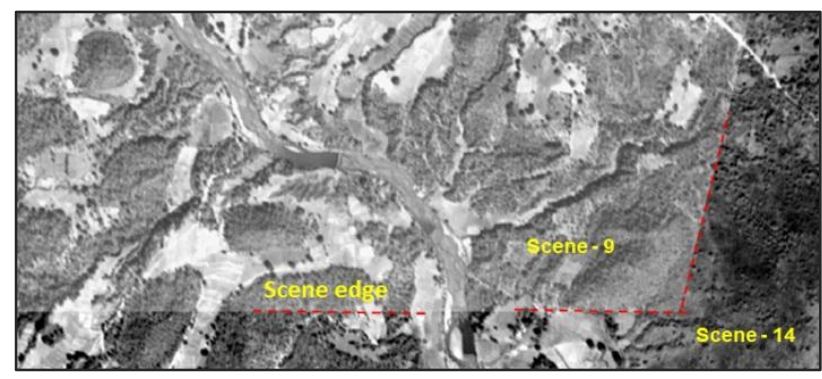

Fig-5. Feature continuity in adjacent scenes based ortho outputs

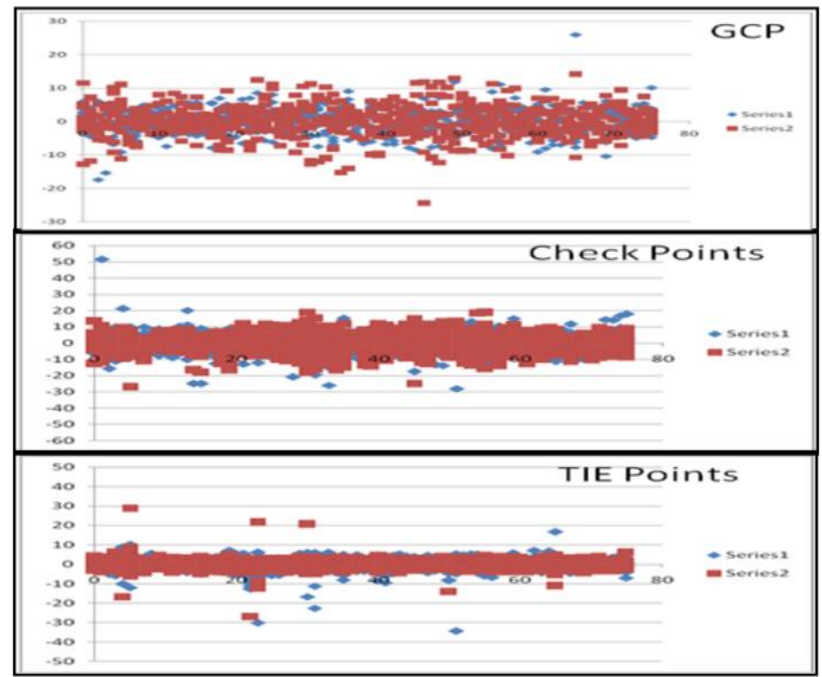

Fig-6 GCP, checkpoints and tie-points in X \& Y direction

Error distribution in GCP, check points, and tie points (Fig-6) helps to verify ADIF information, RPC quality and any other inherent bias/ discrepancy in input data sets. 


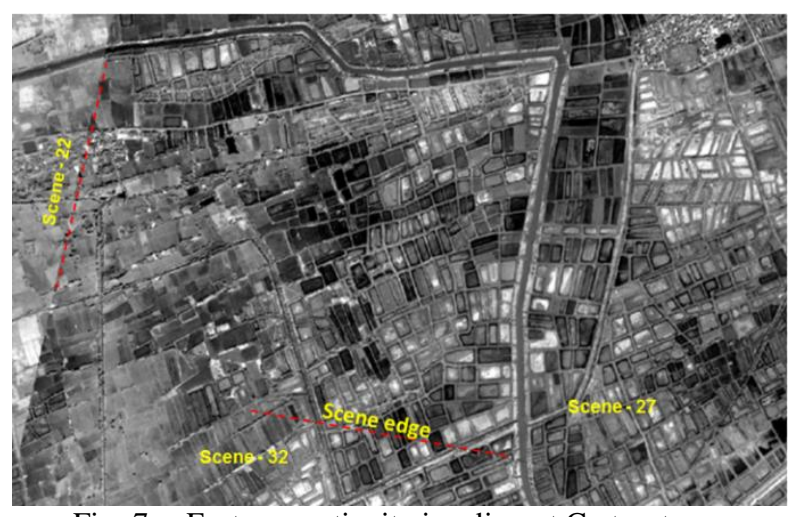

Fig -7a. Feature continuity in adjacent Cartosat scenes processed in a single block at coastal area.
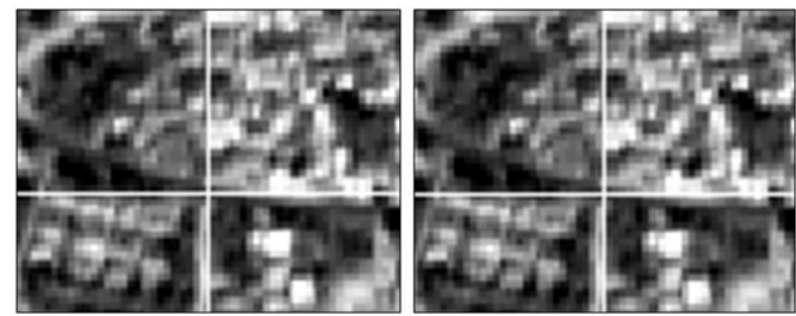

Fig-7b. Example of geometric accuracy when displaying two adjacent scenes together through geo-linking

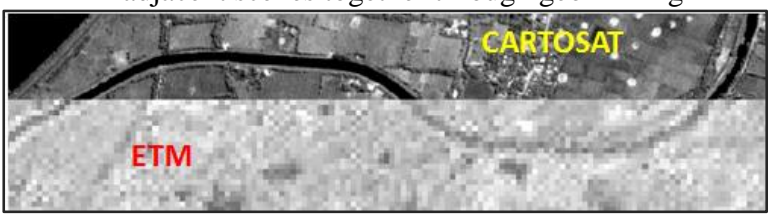

Fig-7c. Feature continuity of otho product with reference data

A slightly modified Single block processing of 25 rows and 2 columns Cartosat-1 imagery belonging to same area indicate that relative error is within $10 \mathrm{~m}$ among adjacent Cartosat scenes (Fig-7a and $7 \mathrm{~b}$ ) but $18 \mathrm{~m}$ to $48 \mathrm{~m}$ with reference ETM data (Fig-7c). High resolution reference imagery like Cartosat-1 or Quick-bird ortho is providing better accuracy (within $10 \mathrm{~m}$ ), suitable for large scale mapping and feature extraction.

\subsection{Multi-sensor Block adjustments}

Large area multi-sensor products generated over test area 2 (desert) and test area 5 (high mountain) with multiple scenes.

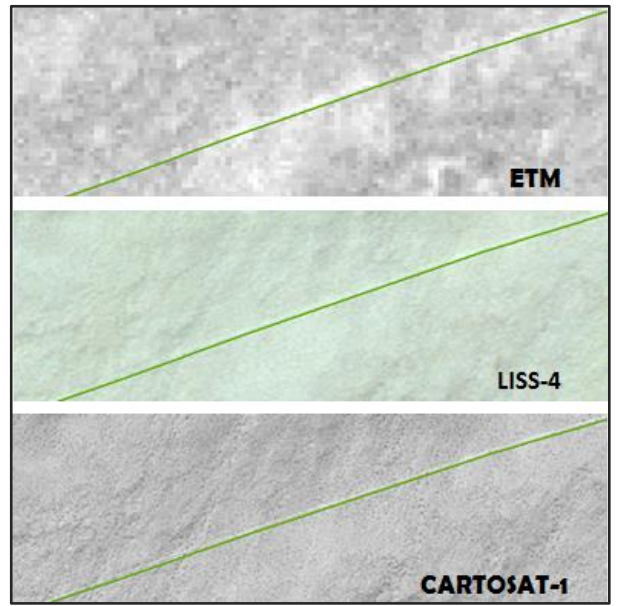

Fig-8a. Example of geometric accuracy with overlaid vector data (road in green line) over multi-sensor outputs scenes
A vector layer (track) is generated from LISS-4 data and overlaid on cartosat-1 output ortho as well as on reference ETM data. The alignment of track at different raster output indicates the geometric accuracy of products. Multi-sensor single Block processing at test area -2 assures the (Fig-8b) pixel tagging with geometric fidelity.
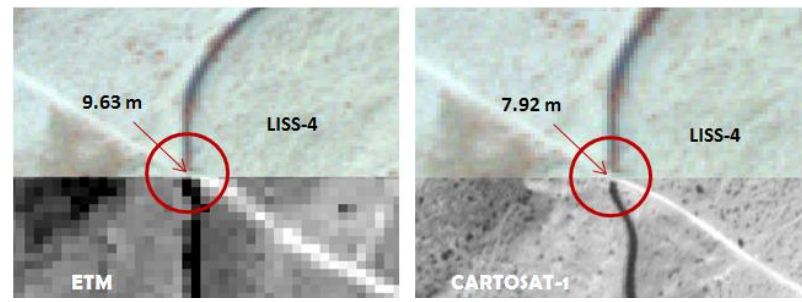

Fig- 8b. Geometric accuracy at multi-sensor block output

The test area 2 achieves an RMSE of \pm 15 m moderately undulating desert terrain and Ortho correction with control points from ETM-pan data can give a planimetric accuracy of \pm $30 \mathrm{~m}$ for entire block without any specific error bias. Observable error in moderately undulated areas is less than $\pm 20 \mathrm{~m}$. Pixels tagging among multi-sensor, multi-resolution, multispectral products are useful to provide better detail and increased accuracy for applications like forest and land-use monitoring

\subsection{Radometrically balanced/mosaic ready scenes}

Radiometric artefacts at ortho products at the mountain shadow area (Fig-9a) is reported and subsequently rectified in the BBA system. Another observation was up to 2-3 pixels of radiometric band to band mismatch (BBR) are observed in one LISS-4 scene of Bengaluru. No Radiometric band to band mismatch is observed in data products of AWiFs or LISS-3.

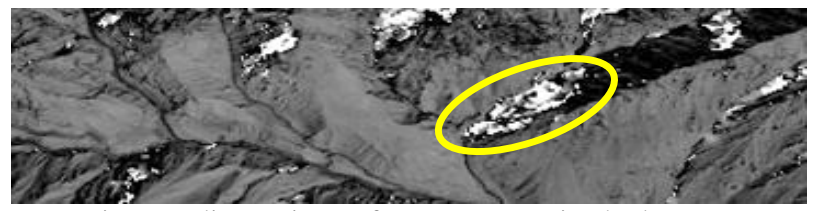

Fig-9 Radiometric artefacts at mountain shadow area
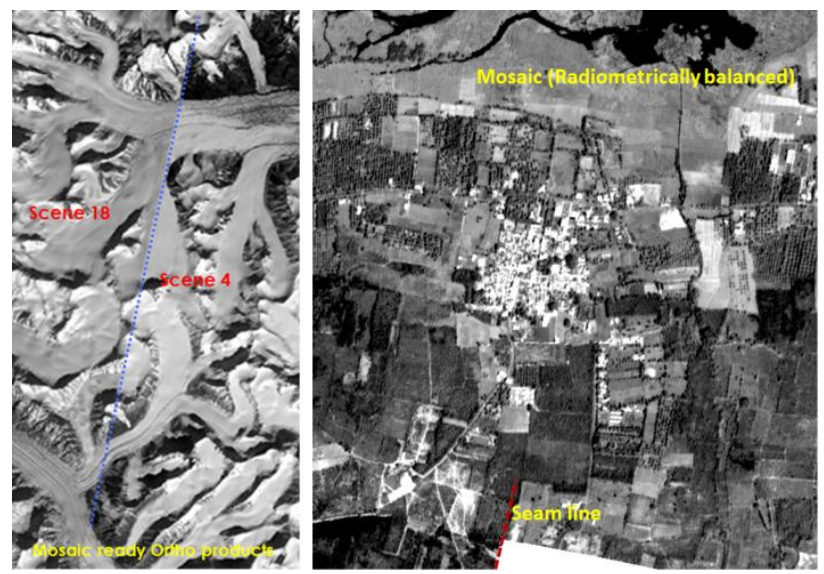

Fig-9b. Radiometrically enhanced mosaic ready products

Output Cartosat Ortho products are radiometrically enhanced mosaic ready scenes for generating seamless large area mosaic. Fig -9b shows the enhanced products of two areas-a) mountainous area covering glaciers and shadows (left side) and b) flat area with crop, water body and settlement (right side). The dotted seam lines are indicating the scene extent. 


\subsection{Overall observations}

Following are the salient features of this exercise-

- Good feature continuity with minimal internal distortion is observed in plain area as well as in high and moderately hilly terrains.

- Multi-sensor block triangulation can assure better geometric accuracy and feature continuity across a fairly large number of scenes of high resolution as well as pixel tagging in images from multiple sensors.

- Results indicate that products from input with ADIF information or with Ortho-kit are equal in terms of geometry and radiometry.

- Ortho correction with control points from ETM-pan data can give a planimetric accuracy of $\pm 30 \mathrm{~m}$ for entire block without any specific error bias.

- Error plots confirm that reference datasets of better resolution and accuracy (like Cartosat-1 or Quickbird ortho instead of ETM or LDCM) are more suitable for control points, which is providing better accuracy (within $10 \mathrm{~m}$ ). It is also observed that better spatial resolution of input image assured products with better accuracies.

- Co-registration between different bands of LISS-3 and AWiFs are also taken care and showing better consistency through Block adjustment.

- AOI ortho products, Merged product (Pan + multispectral) and mosaic of pan or multispectral products can be generated within the software environment.

- The tool is able to process Cartosat imagery of entire Maharastra (approx. 600 no) in a single block. and generate 50 no ortho products per hour with minimal human intervention.

\section{CONCLUSIONS}

The software is suitable to make products from medium resolution to very high resolution satellite data and be able to cater the need of future missions. The spatial consistency and positional accuracy of single/ multi-sensor Ortho-corrected products has been significantly improved through the use of Bundle Block Adjustment. Further investigations should be done regarding the statistical evaluation of the product with surveyed controls and understanding the correlation of error distribution in block level as well as in scene level with absolute accuracy.

\section{ACKNOWLEDGEMENT}

The authors are thankful to BBA evaluation team for their contributions and development team for providing clarifications time to time during the valuation phase.

\section{REFERENCES}

Agular M.A et al, 2008. Geometric accuracy assessment of the orthorectification process from very high resolution satellite imagery for Common Agricultural Policy purposes. In International Journal of Remote Sensing, Vol. 29, No. 24, 20 pp 7181-7197

Agugiaro G. et al. 2012. Geometric evaluation of very high resolution satellite imagery. In Trento International Archives of the Photogrammetry, Remote Sensing and Spatial Information Sciences, Volume XXXIX-B1

Cheng P., Toutin Th., et al. 2003. QuickBird - geometric correction, path and block processing and data fusion. In EOM, Vol. 12, No 3 , May, pp. 24-30
Crespi Mattia et al, 2009. A Procedure for High Resolution Satellite Imagery Quality Assessment. www.mdpi.com/journal/sensors, ISSN 1424-822.

Dial Gene.2003. IKONOS satellite, imagery and products In Remote sensing of environment 88 (2003), pp.23-36.

Eugene Rose et al. 2005. Multi-sensor triangulation In ASPRS 2005 Annual Conference, March 7-11, Baltimore, Maryland.

Ghosh Sujata et al, 2014. Geo-spatial techniques and data products for natural resource management in Himalayan terrain in IGU,June, Srinagar, India.

Grodecki J et al, 2003. Block adjustment of high resolution satellite images described by rational polynomials. $P E \& R S$, vol.69, No.1, pp. $59-68$

Jacobson K. Block adjustment. In http://www.ipi.uni-hannover.de

J. Chmiel et al. 2004. Orthorectification and geometric quality assessment of very high spatial resolution satellite imagery for common agricultural policy purposes.

S. Muralikrishnan et al, 2004. Geometric quality assessment of cartosat1 data products. In ISPRS Commission IV, WG IV/9

Nagasubramanian V et al, 2007. Rational function model for sensor orientation of IRS-P6 Liss-4 imagery. The Photogrammetric Record, 22(120),pp 309-320

Novák D. 2009. Orthoserv - quality assessment for orthorectified and coregistered Satellite image products

Radhadevi P.V. et al. 2010. New Era of Cartosat Satellites for Large Scale Mapping,2010 Photogrammetric Engineering and Remote Sensing., vol 76, No. 9, pp. 1031-1040,

Sampath Aparajithan,2010. Geometric evaluation and validation of aerial and satellite data using Sioux Falls validation test range. In ASPRS 2010 Annual Conference. Sandiego, California

User Manual, 2014. Multi sensor Block adjustment and production system - ADRIN, Secunderabad. 